Ensino, Saúde e Ambiente -V5 (2), pp. 33 -44, ago. 2012

\title{
ABORDAGENS DISCURSIVAS EM EVENTOS DE CIÊNCIAS: contribuições sobre identidades profissionais docentes
}

\section{DISCURSIVE APPROACHES IN SCIENCE EVENTS: contributions on teachers professional identities}

\author{
Maria Cristina Ribeiro Cohen \\ criscohen@gmail.com \\ cristina.cohen@ufvjm.edu.br
}

Universidade Federal dos Vales do Jequitinhonha e Mucuri/ UFVJM

Faculdade de Ciências Biológicas e da Saúde / Departamento de Ciências Biológicas

\begin{abstract}
RESUMO
Neste estudo, busco caracterizar como professores envolvidos em espaços escolares e que circulam em eventos acadêmicos se situam como autores e enunciadores de narrativa própria em textos sócio-situados. O quadro teórico-metodológico, orientador dos procedimentos analíticos e as coordenadas filosóficas desenvolvidas por M. M. Bakhtin (1986, 1975/1988 e 1979/2003) possibilitam compreender a multiplicidade de vozes presentes em diversas esferas discursivas. Considero as experiências docentes com o discurso científico da área de Educação em Ciências como um fator relevante para o entendimento e apropriação de uma cultura própria por aqueles que se interessam em participar na produção e circulação na esfera acadêmica; ou seja, ser reconhecido por um grupo específico de agentes dessa prática social. Nesse sentido, assumo que formas de aproximação e interlocução entre pesquisa e prática docente podem ocorrer em múltiplos espaços institucionalizados, como podem se dar por meio da criação de contextos de integração entre diversos perfis - evento acadêmico.
\end{abstract}

Palavras - chave: autoria - análise de discurso - formação continuada de professores.

\begin{abstract}
In this study, I characterize how teachers involved in school and circulating in academic events lie as authors and enunciator of narrative texts in their own socio-located. The theoretical and methodological, analytical procedures and guiding the coordinates philosophical developed by M. M. Bakhtin (1986; 1975/1988; 1979/2003) allow to understand the multiplicity of voices present in different spheres of discourse. I consider teaching experiences with scientific discourse in the area of Science Education as a factor relevant to the understanding and ownership of their own culture by those who are interested in participating in the production and circulation in the academic sphere; $i$ $\mathrm{e}$, be recognized by a group specific agents of social practice. In this sense, I assume that forms of approach and dialogue between research and teaching practice can occur in multiple institutionalized spaces, as can be occur through the creation of contexts of integration between diverse profiles - academic event.
\end{abstract}

Key words: authorship - discourse analysis - teacher professional development. 


\section{Introdução}

As orientações analíticas no campo da pesquisa em Educação em Ciências (LEMKE, 1990, 1997 e 2000; MARTINS, et al, 2007; e MORTIMER, 1998) apontam específicos eixos nos estudos que envolvem registros discursivos. A saber: (i) partem de uma visão de linguagem que reconhece suas dimensões comunicativa e constitutiva; (ii) buscam, nas abordagens sócio-histórico-culturais, respostas sobre demandas que envolvem o papel da linguagem; (iii) problematizam as condições sociais de produção; e (iv) discutem os contextos de utilização e inserção destes impactos em diversas práticas educativas em ciências. Além dessas concepções, destaco a necessidade de compreender a conformação e a articulação de saberes e práticas em diferentes níveis de percepção junto aos sujeitos em seus processos discursivos, com o propósito de indagar e entender, através dos diversos discursos docentes, "vozes sociais, objetos, sentidos, valores, formas de representação e expressão e valores constituintes de seus dizeres" (COHEN, 2004; COHEN e MARTINS, 2008).

Organizo, nesta perspectiva, a presente teorização - para quem os professores destinam seus discursos, em que medida estes se aproximam ou se afastam dos universos discursivos - acadêmico e escolar e quais impactos tais aproximações e afastamentos têm em suas formações identitárias e profissionais. A partir do diálogo instaurado, quais fragilidades ou contradições ou impasses, seus discursos são reveladores dos papéis desempenhados e consequentemente, dos lugares ocupados por formadores e pesquisadores da área de Ensino de Biologia. Estas implicações voltam-se para as competências $^{1}$ e reflexão de saberes docentes e as entendem como socialmente construídos e partilhados por conta de processos de imersão em mundos socializados diversos - familiar, escolar, acadêmico, entre outros.

Apresento, neste estudo, indicativos da posição axiológica enquanto efeito de sentido produzido pelo próprio campo da comunicação cultural (BAKHTIN, 1979/2003, p. 299) ao considerar que os Encontros promovidos por sociedades científicas e/ou profissionais ${ }^{2}$, ao reunir diversos perfis profissionais, configuram-se como espaço de troca, revelador de diálogo entre esferas sociais distintas - acadêmica e escolar. Com

\footnotetext{
$1 \quad$ Há um repertório de competências adquirido com o tempo e com a experiência de trabalho, tais como competências ligadas à própria ação pedagógica (para os professores, consideradas as de maior importância), competências de liderança, de gerenciamento, de motivação. Competência entendida como saber-ensinar (TARDIF; RAYMOND, 2000).

2 São exemplos desses eventos o Simpósio Nacional de Ensino de Física, realizado desde 1970 e o Encontro "Perspectivas do Ensino de Biologia" / EPEB, organizado pela Faculdade de Educação da Universidade de São Paulo desde 1984.
} 
isto, significa expor enunciados que circulam em Encontros de Ensino de Biologia e como estes se expressam em artigos acadêmicos autorados por professores.

Artigos acadêmicos são exemplos de gêneros razoavelmente estáveis associados a práticas tais como pesquisa científica e ensino escolar. Estes produtos discursivos, bem como revistas e periódicos são vistos como artefatos de natureza social e constituintes de referência ${ }^{3}$ para especialistas envolvidos na esfera acadêmica. Ressalto os aspectos de intervenção na constituição dos gêneros discursivos e no modo como se distinguem entre si e os caracterizo. A saber: (i) o suporte da enunciação - Atas do evento acadêmico; (ii) a inserção das enunciações - resumo e artigos; (iii) o papel social do falante/ autor - artigos assinados; (iv) os propósitos comunicativos de locutores/ autores e, por fim, (v) a estrutura organizacional propriamente dita.

Em busca de integrar distintas abordagens discursivas e como estas contribuem para o entendimento das construções de identidades profissionais docentes, teço algumas considerações acerca (i) da multiplicidade de vozes (o caráter dialógico) presentes nos discursos docentes ${ }^{4}$ e (ii) de evidências de que estes sujeitos não falam de um único horizonte sócio-conceitual (BAKHTIN; 1986, 1975/1988 e 1979/2003).

De acordo com Freitas (2002, p. 28), trabalhar com a pesquisa qualitativa numa abordagem sócio-histórica consiste numa preocupação de compreender os eventos investigados, descrevendo-os e procurando as suas possíveis relações, integrando o individual com o social. Isso não quer dizer que seja a única posição possível para as produções discursivas relacionadas socialmente à esfera acadêmica. As identificações de padrões enunciativos presentes nas produções docentes possibilitam caracterizar vinculação às premissas assinaladas nas quatro edições presentes nas Atas do Encontro ${ }^{5}$ : (i) compreender melhor as necessidades dos profissionais da área, (ii) legitimar práticas constituintes da identidade docente, (iii) consolidar espaços dialógicos, (iv) identificar a pluralidade de ideias e a troca de experiências entre os diversos níveis, bem como (v) aproximar cada vez mais saberes acadêmicos e saberes escolares.

\section{Critérios de delimitação}

\footnotetext{
3 Muitas vezes veiculados por meio das circulares de eventos acadêmicos e/ ou através de normas de submissão para publicação de artigos ou de capítulos de livros, especificadas pelo comitê editorial.

4 Sempre que for mencionado, será em alusão ao professor de ciências / biologia da escola básica, especificamente.

5 O recorte temporal tem por base as quatro edições do Encontro realizadas no estado do Rio de Janeiro, entre 2001 e 2007.
} 
Em busca do(s) perfil(is) de professores que se empenham como autores, seleciono os trabalhos produzidos exclusivamente por professores da escola básica, reconhecidos como um dos partícipes da comunidade dos associados da SBEnBio. ${ }^{6}$ Destaco que a classificação dos artigos respeitou a caracterização emitida pelo professor ao seu texto, a partir de orientações contidas nas normas de submissão explicitadas em circulares enviadas nas divulgações de cada edição do Encontro ${ }^{7}$. Os materiais empíricos que servem de base para a construção dos dados constituem-se nas enunciações de professores que participaram pelo menos, em duas das quatro edições por considerá-los envolvidos e compromissados com os propósitos do Encontro acadêmico.

\section{$O$ professor que aceita o convite e investe no encontro acadêmico}

De acordo com FISHER (2007, p. 23) há dois entendimentos teóricos vinculados ao processo e modos de significar através do registro escrito: um indicador de que há uma disposição geral para a escrita, que se esta estiver bem desenvolvida, dará condições aos sujeitos de produzir de forma adequada qualquer discurso; e um segundo que pressupõe que aprender a organização estrutural habitual de um conjunto de indicações pertencentes a um específico gênero, os tornam proficientes em relação a um discurso constituído (e constituinte) pela esfera de referência.

O reconhecimento de relações e tensões entre esferas de atividade humana diversas acadêmica e escolar - torna-se revelador de um desejo do professor da escola básica de se fazer ouvir, e, com este propósito, buscar apropriar-se das formas de produção da esfera acadêmica. Também reconhece que a linguagem escrita tem papel primordial no meio acadêmico - quer seja porque a escrita é entendida como uma maneira eficiente de fazer persistir os discursos através dos tempos, das diversas épocas, quer seja por sua condição de legitimação.

Sendo assim, é preciso que o professor perceba estes reconhecimentos e buscas como um convite. Ao estruturar seus artigos com subtítulos genéricos, comumente observados em relatos priorizados por esta esfera sócio-ideológica, tais como introdução, desenvolvimento e conclusões, o professor com o desejo de pertencimento à comunidade de pesquisadores é chamado a investir ao aceitar o que é proposto pela enunciação.

\footnotetext{
6 In: Anais do I EREBIO - RJ/ ES 02, 2001, p. 20.

A partir das modalidades definidas pelos comitês científicos das quatro edições do evento e ao utilizar como critério de delimitação do corpus o perfil de pertencimento à esfera escolar, foram identificados entre os seiscentos e quarenta e oito trabalhos aceitos e publicados nas quatro Atas, trinta e dois trabalhos produzidos por professores da escola básica.
} 
Segundo a fundamentação bakhtiniana, a noção de efeitos de sentidos decorre do entendimento do próprio sentido, ou seja, como algo em movimento dialógico, realizado através de embates interpretativos e que no estabelecimento de correlações vai se (re)definindo. Por exemplo, não demandados pelas circulares do evento, estes indicativos [estrutura composicional] e acréscimos [parte pré-textual - "Resumo”] demonstram a preocupação de Ana (T 1) em sua elaboração discursiva. Outro exemplo a ser destacado por ser muito aceita nos textos argumentativos é a forma de enunciar adotada por Carla (T 4), ao utilizar-se de alguns parâmetros para classificar as incertezas de seus alunos e, adotar a expressão "parece ser" com recorrência. Este modo de dizer revela uma tendência à linguagem despersonalizada comumente observada nos textos acadêmicos, científicos. Importante, também, notar a tendência ao uso da partícula se em gêneros acadêmicos, que contribui sobremaneira para a objetividade exigida não só pela esfera discursiva, mas também pelo próprio tema em questão. Por exemplo: "Percebe-se ${ }^{8}$ uma grande confusão acerca de assuntos ligados à sexualidade por parte dos adolescentes, isto fica evidenciado [...]”. Deste modo, a construção discursiva atende às intenções persuasivas que permeiam o gênero discursivo em particular e confere autoridade ao que ao enunciado.

Portanto, considero que no uso de determinados recursos discursivos, com sentido de indeterminação do enunciador, os professores ratificam seu posicionamento e criam um distanciamento revelador de condições de objetividade presentes nos discursos acadêmicos.

\section{O professor que compartilha propósitos comunicativos com sua audiência}

$\mathrm{O}$ modo com o autor/ escritor se apropria das informações sobre o universo que o cerca e as incorpora em seu repertório, ao descrever e avaliar por meio da linguagem é função de própria condição humana, porém moldada pela interação dialógica com o mundo. A partir de uma expectativa interlocutiva específica, estes sujeitos buscam estabelecer um vínculo dialógico com as obras consultadas, com as ideias dos autores das obras; ou seja, com outros discursos da comunidade de educadores em ciências. Através das referências consultadas assim como da apropriação dos padrões normativos de formas de inclusão e funções mencionadas pelos professores, as escolhas dos créditos ou acolhida à palavra de autoridade possibilitam revelar a necessidade de partilhar saberes.

$8 \quad$ Grifos meus. 
Nesse sentido, considero que as realizações textuais e discursivas, como evocações ${ }^{9}$, referências, citações, paráfrases etc, encontram-se relacionadas à percepção de uma necessidade de legitimação do discurso docente por meio da aderência a um outro discurso de autoridade. A seguir, uma breve apresentação das publicações identificadas e/ ou que fundamentam as produções docentes e suas configurações:

\begin{tabular}{|c|c|c|}
\hline \multicolumn{2}{|c|}{ Publicações identificadas e que serviram de fundamentação para as produções docentes } & Configuração \\
\hline \multirow[t]{4}{*}{ Documentos oficiais. } & Parâmetros curriculares Nacionais: ensino médio/ PCNEM. & $\begin{array}{l}\text { Paráfrase e citação } \\
\text { direta }\end{array}$ \\
\hline & $\begin{array}{l}\text { Parâmetros Curriculares Nacionais: primeiro e segundo ciclos do } \\
\text { ensino fundamental. }\end{array}$ & $\begin{array}{l}\text { Citado nas } \\
\text { referências } \\
\text { bibliográficas }\end{array}$ \\
\hline & 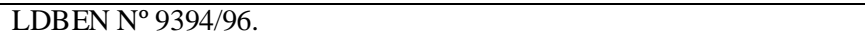 & Citação direta \\
\hline & Ministério da Saúde / OMS. & $\begin{array}{l}\text { Citação direta e } \\
\text { indireta }\end{array}$ \\
\hline 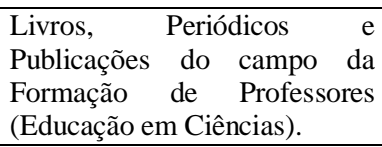 & $\begin{array}{l}\text { KRASILCHIK, M. (1986) Prática de Ensino de Biologia. } 2^{\text {a }} \text { Ed. São } \\
\text { Paulo: Editora Harper \& Row do Brasil. }\end{array}$ & Paráfrase \\
\hline Artigo jornalístico. & Lins, R. N. O sexo culpado. In: Vida/ Jornal do Brasil. RJ, 18/04/1999. & Citação indireta \\
\hline \multirow{8}{*}{$\begin{array}{l}\text { Livros, Periódicos. } \\
\text { Publicações de diversas áreas. }\end{array}$} & $\begin{array}{l}\text { ACSERALD, H. et ali (1993) Ecologia: direito do cidadão. Coletânea } \\
\text { de textos. Rio de Janeiro: Gráfica do Jornal do Brasil. }\end{array}$ & Citação direta \\
\hline & $\begin{array}{l}\text { GUTIERREZ, F.; PRADO, C. (2000) Ecopedagogia e Cidadania } \\
\text { Planetária. Guia da Escola Cidadã. Instituto Paulo Freire. } 2^{\mathrm{a}} \text { Ed. São } \\
\text { Paulo: Cortez. }\end{array}$ & Citação indireta \\
\hline & $\begin{array}{l}\text { PEDRINI, A. de G. (org.) (1997) Educação ambiental: reflexões e } \\
\text { práticas contemporâneas. Petrópolis. Rio de Janeiro: Editora Vozes. }\end{array}$ & Citação direta \\
\hline & $\begin{array}{l}\text { McLELLAN, T; BRAGG, A. \& CACCIOLA, J. (1988). Tudo sobre } \\
\text { drogas, ansiedade e stress. São Paulo: Nova Cultural. }\end{array}$ & Paráfrase \\
\hline & $\begin{array}{l}\text { POOLE, C. (1976) Contraception and the adolescent female. The } \\
\text { Journal of School Health. } 46: 475-479 \text {. }\end{array}$ & Paráfrase \\
\hline & $\begin{array}{l}\text { QUINTAS, J.S. (1996) Meio ambiente e cidadania. Educação } \\
\text { Ambiental. } \text { N }^{\circ} \text { 5. Cadernos do NERU. Cuiabá: EdUFMT. }\end{array}$ & Citação direta \\
\hline & $\begin{array}{l}\text { SANTROCK, J. W. (1990) Adolescence. New York: W.C. Brown } \\
\text { Publishers. }\end{array}$ & Paráfrase \\
\hline & $\begin{array}{l}\text { WEEKS, J. (1993) El malestar de la sexualidad. Significados, mitos y } \\
\text { sexualidad. Madrid: Talasa Ediciones. }\end{array}$ & Paráfrase \\
\hline
\end{tabular}

É pelo jogo entre estabilização e desestabilização; ou seja, pelos dois movimentos no interior da língua, que o discurso revela aquilo que de alguma forma resiste. Esta caracterização se justifica, principalmente por meio das referências consultadas assim como da apropriação dos padrões normativos de formas de inclusão e funções mencionadas pelos professores, as escolhas dos créditos ou acolhida à palavra de autoridade possibilitam revelar a necessidade de partilhar saberes. $\mathrm{O}$ aspecto que diz respeito a referenciação é considerado relevante em função das atividades de escrita

9 Quando o professor/ enunciador faz referência a um fato da experiência cotidiana escolar ou a um evento que supõe ser (re)conhecido e/ ou compartilhado por seus interlocutores. 
serem aquelas pelas quais o professor constrói seus conhecimentos na área, sendo orientado pelo interlocutor/ destinatário presumido - o parecerista, o leitor/ produtor de textos mais experiente desse específico contexto. Por conseguinte, destaco que as referências bibliográficas selecionadas e materializadas nos registros escritos fazem parte do universo discursivo do professor que participa de eventos na área de ciências que tiveram contato com estas obras e que estas escolhas permitem identificar os sujeitos preferenciais da audiência aos quais os professores das produções discursivas analisadas se dirige.

\section{Como os professores se apresentam}

Os resumos publicados nas Atas do evento acadêmico configuram-se, mais comumente, pela aproximação e do que pelo distanciamento do professor ao seu objeto ou questões de estudo ou de relato. Por exemplo, o emprego recorrente dos tempos verbais torna-se indicativo de como os autores colocam-se próximos das questões de interesse e ao se identificarem, revelam-se como quem escreve o gênero artigo. Na subseção “Conclusão" ao prescrever a atuação dos “educadores” em estratégias que integrem as ações dos campos da Saúde e da Educação e especificamente das ações promotoras de saúde - “[...] pois temos ${ }^{10}$ a oportunidade estando mais próximos deles. E juntamente com os profissionais de saúde, esclarecendo-os, [...]” (Joyce / T 2) e, ao final da subseção “Introdução”: “[...] quando ensinamos estamos trocando experiências já vivenciadas por $\underline{\text { nós, }}$ educadores ${ }^{11}$, e para isso, precisamos sempre buscar estratégias às vezes não convencionais mas bem criativas" (Ana / T 1).

Além dos exemplos de formas de aproximação, há que se considerar as formas pelas quais os autores de resumos acadêmicos manifestam nos vários fragmentos discursivos, maior e/ ou menor distanciamento, direto e/ou indireto, com a questão apresentada e discutida. Em momentos distintos, o autor ao se expressar, revela marcas de distanciamento e do seu posicionamento. Por exemplo: na subseção "Comentários finais”, a professora Carla (T 4) tece críticas ao desempenho dos profissionais de saúde e dos pais e adverte sobre "Outro ponto que chama atenção é falta de clareza quanto ao uso da pílula, o que poderia ser sanado pela leitura da bula ou a conversa com o médico" e finaliza enunciando que cabe a "outros" a incumbência "da tarefa educativa dos pais”.

$11 \quad$ Grifos meus. 
As marcas de distanciamento também são identificadas quando são empregados alternadamente tempos verbais na $3^{\text {a }}$ pessoa do plural ou do singular; bem como os índices de indeterminação do sujeito, ao fazer referências aos alunos - "os papéis com perguntas foram sendo entregues para que a professora lesse em voz alta (sugestão deles) e os alunos ou a própria professora respondesse ${ }^{12}$ " (Carla / T 4).

Além do uso de tempos verbais específicos, o uso de aspas é marca usual de distanciamento, de não concordância com o termo ou o segmento de texto que se aspeia, segmento esse produzido por ou atribuído a outro enunciador. Assim, o que se aspeia encerra a voz de outro enunciador e mostra a não concordância do locutor com o que essa voz enuncia. Por exemplo, em vários momentos de seu discurso, a professora revela a sua não concordância com os termos ditos por seus alunos - o outro enunciador, tais como 'normal', 'perda', 'coisa errada', entre outras.

Considero, portanto, que os movimentos de (re)significação executados indicam percursos de aproximação, de alinhamento ou de afastamento; porém todos estão em contínuos movimentos no que diz respeito a tal lugar enunciativo, construído sóciohistoricamente.

O professor que encontra no jogo irônico uma forma de resistência em virtude de conflitos com as diretrizes institucionais

Com relação ao sujeito que acolhe o jogo irônico no interior do seu discurso, Bakhtin (1975/1988, p. 105) afirma que "as palavras não são dele, se as compreendermos de maneira direta, porém, pertencem a ele, quando transmitidas ironicamente, postas em maior ou menor evidência, ou seja, percebidas a uma distância conveniente”. Segundo BRAIT (1999), a ironia possibilita visualizar formas de relações estabelecidas entre discurso, instituição e história pela argumentação crítica e indireta. Há que se considerar que a percepção do não-dito se dá pelo contexto extraverbal, que é composto por índices sociais de valor e que interpretar o jogo irônico presente nas produções docentes implica identificar as relações que esses professores mantêm com as filiações sóciohistóricas, com a subjetividade e a alteridade, em um constante movimento de ressignificação discursiva.

Muitas vezes, os autores de textos acadêmicos estabelecem relações de concordância entre o que se disse e o que se queria dizer. Nos textos irônicos, os discursos estabelecem uma relação de discordância entre o que se disse e o pretendia dizer. É a situação histórica vivenciada pelo professor que lhe permite perceber esta ou aquela

12 Grifos meus. 
Ensino, Saúde e Ambiente -V5 (2), pp. 33 -44, ago. 2012

possibilidade enunciativa dentre as múltiplas possibilidades criadas pelo contexto situacional. Como acontece tanto no texto da professora Carla (T 4) ao se referir aos "outros" quanto ao modo com que Joyce ( $\mathrm{T}$ 2) trabalha a citação 13 "Ministério da Saúde adverte: o álcool faz mal à saúde, causa alcoolismo, cirrose, câncer...”, na utilização da paródia como recurso, efeitos irônicos são produzidos. Os sentidos "professores" no discurso de Carla e - "Ministério da Saúde adverte: o fumo faz mal à saúde, causa..." no discurso de Joyce, são presumidos, compartilhados, apesar de ressignificados. Ressalto que a (re)significação dos enunciados indicia uma forma de resistência e de preocupação decorrente do lugar social ocupado em relação às diretrizes e prescrições no âmbito da saúde da população e das questões acerca da sexualidade dos adolescentes de um modo geral e em particular, da comunidade escolar - afetada tanto pelos prejuízos advindos dos comportamentos e exposições aos riscos quanto pela omissão de ações educacionais constantes voltadas para esta faixa geracional.

O professor disposto a estabelecer parcerias para execução de propostas coletivas Em suas produções discursivas, os professores enfatizam a importância do trabalho coletivo, na instituição de parcerias e consequente consolidação com outros profissionais, para além de parceiros da área de Ensino de Ciências/ Biologia. Evidências acerca destas compreensões estão assinaladas no artigo de experiências docentes assinado por Ana (T 1) ao explicitar que “... desenvolve a atividade com mais duas professoras das áreas de Biologia e Sociologia” e que ao envolver alunos, destaca este específico aspecto - o empenho coletivo. Além deste enfoque, a professora sugere a promoção de situações curriculares de natureza interdisciplinar e afirma que “[...], no que diz respeito à ação do cidadão consciente e atuante e sua relação com a educação ambiental, já que esta tem a capacidade de atender várias interfaces, tais como: meio ambiente, educação, cidadania, saúde, entre outras, podendo ser vista com um olhar sociológico”.

\section{De onde falam os professores}

De acordo com Bakhtin (apud COHEN e MARTINS, 2008, p. 54), cada pessoa possui um horizonte social, que é determinado pelo pertencimento a uma comunidade discursiva e que direciona o modo de interpretar e de dialogar, assim como seu posicionamento ideológico frente a uma determinada questão. Em concordância com as concepções de Jobim e Souza (2001, p. 114) ao afirmar que "a simples tomada de consciência, mesmo que confusa, de uma sensação qualquer, (...) pode dispensar uma

Grifos meus. 
Ensino, Saúde e Ambiente -V5 (2), pp. 33 -44, ago. 2012

expressão externa, mas não dispensa uma expressão ideológica”, considero que os professores expressam e assumem ideologicamente suas posições ao compartilharem significados sociais e propósitos comunicativos e, que a partir deste empreendimento discursivo, avaliam e dialogam com a audiência social do Encontro - professores de ciências/ biologia, profissionais da área de saúde, educadores ambientais, alunos da graduação e da pós-graduação, professores universitários, entre outros.

\section{O professor que difunde saberes a outros ouvintes}

Os objetos do mundo são apreendidos não como dados primeiros e imediatos, mas como produtos construídos por uma competência significante, simbólica e semiótica (FIORIN, 1997, p. 31). Para Bakhtin (VOLOCHINOV, 1986, p. 34), “A consciência só se torna consciência quando se impregna de conteúdo ideológico (semiótico) e, consequentemente, somente no processo de interação social”. Ao ter responsabilidades do conhecimento da prática do domínio da língua, de ascender a uma realidade histórica e a uma produtividade cultural, e por meio dos processos de escrita, participar como membro de um grupo social, de uma classe, tal assunção sugere a inserção dos discursos docentes num determinado contexto situacional - eventos acadêmicos em ensino de ciências/biologia, em que o professor apreende os lugares e os signos sociais, isto é, os princípios fundantes da própria posição autoral, instaurando uma posição de responsividade. Estes esforços estão presentes quando ressaltam experiências com propósitos de motivar o interesse, a interatividade e o engajamento dos alunos, a partir de suas concepções. Ao levar essas múltiplas visões em consideração, estes docentes passam a estruturar e fazer intervenções em específicos saberes que envolvem os aspectos abordados - temas associados a juízos de valor, a aspectos sócio-culturais, que trazem implicações no papel exercido pelo professor de ciências/ biologia. Sendo assim, o professor encontra-se na perspectiva da posição daquele que, (re)conhecendo os saberes experienciados, pode fazê-los emergir e difundir estes saberes a outros interlocutores/ destinatários. Ao dialogar com os idealizadores do evento, professores e pesquisadores, entre outros, estes docentes buscam relacionar suas considerações com a temática "Formação de professores de Biologia: articulando universidade e escola".

\section{Considerações Gerais}

Novas compreensões e concepções sobre Educação em Ciências e acerca dos discursos sobre saúde e ambiente em específico, que circulam nos espaços escolares incorporam perspectivas que estão aos poucos ganhando espaços, em diversos contextos e práticas sociais (SANTOS e WESTPHAL, 1999; OLIVEIRA, 2001; COHEN, 2004; SCHALL, 
2005; COHEN e MARTINS; 2003 e 2008). Na perspectiva bakhtiniana, os aspectos que constituem um texto como enunciação, são: (i) o projeto discursivo ou vontade discursiva; isto é, o falante/ autor e seu querer dizer bem como a realização deste projeto ao envolver as condições de situação e sua relação com outros enunciados e (ii) os dados da situação social de interação da língua e do gênero discursivo. Assim sendo, identifico na heterogeneidade das produções discursivas, os principais lugares sociais (e, portanto, ideológicos) assumidos e expressos nos discursos docentes - o lugar de autoridade ao elaborarem explicações acerca do mundo da escola ou de partes deste cotidiano.

Ressalto que: (i) os discursos docentes encontram-se intimamente relacionados com os interlocutores previstos e são conduzidos por específicos horizontes avaliativos e por recortes ideológicos que regularizam e significam os gêneros desse constitutivo campo sócio-ideológico; (ii) os protagonistas engajados nas quatro edições do evento acadêmico, ao utilizarem vocabulário específico, encontram-se em condições de igualdade no que diz respeito à linguagem; (iii) os movimentos enunciativo-discursivos elaborados por meio de inserção da palavra de outrem no contexto em questão, configuram a identificação dos diversos campos de atividade e de conhecimento por professores da escola básica; (iv) as produções docentes estão organizadas tendo em vista a promoção de habilidades de leitura desejáveis, como compreender as interrelações discursivas com os conteúdos apresentados em diversos artigos; (v) os múltiplos e variados exemplos de aproximação dos professores a seus contextos escolares manifestam-se em seus registros escritos e, por fim, (vi) essas expressões encontram-se relacionadas à necessidade de legitimação do discurso docente por meio da aderência a um outro discurso de autoridade - o acadêmico.

Por fim, considero que o interesse, motivação e engajamento para circulação dos sujeitos por distintas esferas de atividades humanas - acadêmica e escolar têm implicações com o entendimento da relação constituída ao longo do tempo, entre saber escolar e o saber da pesquisa acadêmica. Na perspectiva de vinculação a uma dada situação social de interação, caracterizo o evento acadêmico promovido pela Sociedade Brasileira de Ensino de Biologia ${ }^{14}$ como lugar de origem e de (relativa) estabilização de novas situações sociais de interação verbal.

\section{Referências bibliográficas}

$14 \quad$ Significada e reconhecida entre sócios e pares pela sigla SBEnBio. 
Ensino, Saúde e Ambiente -V5 (2), pp. 33-44, ago. 2012

BAKHTIN. M. M. (VOLOCHINOV) (1986) Marxismo e Filosofia da Linguagem. 3a Ed. São Paulo: HUCITEC. (original russo de 1929).

BAKHTIN, M. M. (1979/2003) Estética da criação verbal. trad. Paulo Bezerra. São Paulo: Martins Fontes.

BAKHTIN, M. M. (1975/1988) O Discurso no Romance. In: . Questões de literatura e estética. A teoria do romance. Trad. Aurora T. Bernardini e cols. São Paulo: HUCITEC e ANNABLUME.

BRAIT, B. (1999) Análise do discurso e argumentação: o exemplo da ironia. In: MARI, H. et al. (org.) Fundamentos e dimensões da análise do discurso. Belo Horizonte: Carol Borges.

COHEN, M.C.R.; MARTINS, I. (2003) Significando o discurso dos professores sobre educação em saúde: uma análise preliminar. Anais do II Encontro Regional do Ensino de Biologia/ II EREBIO: Formação de professores: articulando universidade e escola. Niterói. RJ. Agosto. Pp. 56-59.

COHEN, M. C. R. (2004) Movimentos enunciativos em projetos de educação em / para saúde: lugar das determinações sociais nos discursos dos professores. Núcleo de Tecnologia Educacional para a Saúde. Universidade Federal do Rio de Janeiro. NUTES/UFRJ (Dissertação de Mestrado).

COHEN, M. C. R.; MARTINS, I. (2008) Discursos de profesores de los ciclos iniciales de enseñanza primaria acerca de las relaciones entre escuela, salud y medio ambiente. Enseñanza de las Ciencias. Revista de investigación y experiencias didácticas. Volumen 26. Número 1. Marzo. Pp. $53-65$.

FIORIN, J. L. (orgs.) Dialogismo, polifonia e intertextualidade. $2^{\text {a }}$ Ed. São Paulo: EDUSP. Pp. $11-27$.

FISHER, A. (2007). Letramento e movimentos interlocutivos na construção do resumo em contexto acadêmico. Revista da Unifebe. $\mathrm{N}^{\circ}$ 5. Pp. $19-32$.

FREITAS, M. T. A. (2002) A ABORDAGEM SÓCIO-HISTÓRICA COMO ORIENTADORA DA PESQUISA QUALITATIVA. Caderno de Pesquisa. No 116. Junho. Pp. 21 - 39.

JOBIM e SOUZA, S. (2001) Infância e linguagem: Bakhtin, Vygotsky e Benjamin. $6^{\mathrm{a}}$ Ed. Campinas. SP: Papirus (Coleção Magistério: Formação e Trabalho Pedagógico).

LEMKE, J. L. (1990) Talking Science. Norwood: Ablex Publishing Corporatio.

LEMKE, J.L. (1997) Aprender a Hablar Ciência: lenguage, aprendizaje y valores. Madrid: Editora Paidós.

LEMKE, J. L. (2000) Articulating Communities: Sociocultural Perspectives on Science Education. Brooklyn College. City University of New York.

MARTINS, I.; MOEBUS, R.; PINHÃO, F.; LIMA, A.; VIEIRA, A. (2007) CARACTERIZAÇÃO DAS POSIÇÕES ENUNCIATIVAS DE AUTORES DE TEXTOS SUBMETIDOS Â REVISTA CIÊNCIA EM TELA: UMA ANÁLISE PRELIMINAR. VI Encontro Nacional de Pesquisa em Educação em Ciências - ABRAPEC. Florianópolis. SC. Brasil. Atas em Cd-rom.

MORTIMER, E.F. (1998) Sobre chamas e cristais: a linguagem cotidiana, a linguagem científica e o ensino de ciências. In: CHASSOT, A.; OLIVEIRA, R. J. (org.) Ciência, ética e cultura na educação. São Leopoldo. RS: Editora Unisinos. Pp. 99 - 118.

OLIVEIRA, M. L. (2001) TRANSVERSALIDADE, CURRÍCULO E SAÚDE: CONSTRUINDO CONHECIMENTO EMANCIPATÓRIO? Anais do I Encontro Regional de Ensino de Biologia (I EREBIO). Novo milênio, novas práticas educacionais? Universidade Federal Fluminense. Niterói. RJ.

SANTOS, J. L. F.; WESTPHAL, M. F. (1999) Práticas emergentes de um novo paradigma de saúde: o papel da universidade. Estudos Avançados. Jan./Abr. vol.13. № 35. Pp.71-88.

SCHALL, V. T. (2005) Educação em saúde no contexto brasileiro. Influências sócio-históricas e tendências atuais. Educação em Foco, Belo Horizonte, v. 1, p. 41-58.

TARDIF, M.; RAYMOND, D. (2000) Saberes, tempo e aprendizagem do trabalho no magistério. Educação \& Sociedade. Ano XXI. No 73. Dezembro. Pp. 209 - 244. (Disponível em: http://www.scielo.br/pdf/es/v21n73/4214.pdf) 